\title{
The Research and Development of Safety Forewarning Composite Integral Strong Geocell
}

\author{
Wang Qingbiao ${ }^{1,2,3}$, Zhang Cong ${ }^{1}$, Wen Xiaokang ${ }^{1}$, Lü Rongshan ${ }^{1}$, Xu Lei ${ }^{1}$, Jiang Jinquan ${ }^{*}$, , \\ Liang Xunmei ${ }^{1}$, Lu Shide ${ }^{1}$, Xie Fei ${ }^{1}$, Zheng Tao ${ }^{1}$, Chen Zhen ${ }^{1}$ and Tang Lingyu ${ }^{1}$ \\ ${ }^{I}$ Department of Resource and Civil Engineering, Shandong University of Science and Technology, Tai'an Shandong \\ 271019, P.R. China \\ ${ }^{2}$ State Key Laboratory of Geomechanics and Geotechnical Engineering, Institute of Rock and Soil Mechanics, Chinese \\ Academy of Sciences, Wuhan 430071, P.R. China \\ ${ }^{3}$ Tai'an Road Engineering Materials Co., Ltd. Tai'an, Shandong Province, 271019, P.R. China
}

\begin{abstract}
In this paper, we have studied the high strength geocell development technology route, analyzed the rules of the tensile properties and creep properties of geocell, and established the relationship between elongation of stress and time, thus providing theoretical foundation for the development and engineering application of the new material. Through theoretical analysis, experimental research and numerical simulation, the characteristics, raw materials and craftsmanship of the geocell have been studied. The research is given on its stress and deformation rules based on elongation test and creep test. The rationality of the experiment is verified through numerical simulation and the conclusions are as follows: (1) With the research on the geocell traditional craftsmanship, combined with new technologies such as special ultrasonic welding technology, intelligent optical fiber technology and fixed locking plate technology, a new-type of safety forewarning high strength geocell can be developed. (2) Based on the geocell material characteristics, the elongation test and creep test are carried out and the tensile yield strength exceeds $250 \mathrm{Mpa}$; the joint is welded by special crafts and the tensile strength $\geq 2000 \mathrm{~N} / \mathrm{cm}$. (3) With FLAC $^{3 \mathrm{D}}$ numerical simulation, simulation study is performed on the mechanical properties of the new cell. Through analyzing the relationship between stress and strain, and time and displacement, the safety design and management construction of the new-type of geocell was proposed based on the actual situation of simulation. (4) The innovation points of the new-type of geocell include: the optimization technique of whole tensile yield strength, fall proof technique of lock parts, and positioning and effective monitoring technique, which effectively solves the geological problems of special projects such as ecological afforestation, sand fixation and high slope soft subgrade, and ensures the quality of the project and has high economic benefits.
\end{abstract}

Keywords: Closed lock parts, creep test, composite integral, FLAC ${ }^{3 \mathrm{D}}$, safety forewarning, tensile test.

\section{INTRODUCTION}

Geocell is a new-type of geosynthetic with high strength, good stability, convenient installation and low price. It is widely used in the reinforcement of foundation engineering and the treatment of soft ground. However, with the increase in the diversity of engineering, geological conditions and construction difficulty, the traditional modified polyolefin geocell currently being used can no longer meet engineering requirements. The engineering construction problems under complex conditions like desertification, high slope and soft ground become increasingly prominent [1-2].

Overseas studies on geocell focus mainly on foundation reinforcement and overall bearing capacity improvement. When used in soft soil foundation treatment, geocell is usually laminated with filling material to add its stiffness strength and reduce its subsidence [3-5]. Some corresponding

*Address correspondence to this author at the Department of Resource and Civil Engineering, Shandong University of Science and Technology, No 223, Daizong Street, Taishan District, Tai'an Shandong 271019, P.R. China; Tel: +86 18805381111; E-mail: 1349725165@qq.com indoor and spot tests have been conducted in this aspect. Zhao Minghua, et al. [6] conducted simulation tests on geocell and created structure system to study the strength of the embankment structure. Wang Guangyue, et al. [7] studied the stability of geocell considering the possible precipitation problems in the construction process and proposed effective measures to improve the flexible supporting stability. Zhao Minghua, Yin Pingbao, et al. [8] applied geocell to specific engineering, conducted a shear test after the compaction of filler and geocell to analyze the shear behavior of structure layer. Bian Xuecheng, et al. [9] used geocell as reinforcement materials functioning on ground, studied its mechanical properties and discussed the force of foundation. Su Yongxue, et al. [10] analyzed the application of reinforced materials to solve the roadbed deformation law with sensitivity analysis method and verified through tests. Song Fei, et al. [11] make numerical simulation on geocell with FLAC $^{3 \mathrm{D}}$, studied the deformation of geocell and analyzed the geocell deformation rule based on the actual results of simulation. What's more, Xie Yongli, Yang Xiaohua, Chang Weitao and Chen Yunmin, et al. [1215] also made some researches on the mechanical properties 
and engineering application of geocell and achieved fruitful research results.

However, in the process of soft soil foundation engineering treatment, with the increase of the complex geology, many possible problems often arise with geocells used in engineering. Some geocells are manufactured with complicated process. Their tensile strength, tear strength and frictional strength are greatly decreased in the process of molding and are not able to meet the design standards and requirements. Some geocells place steel wire mesh in the inner layer and are connected by welding wire in order to increase the strength. Although the integrity is increased, the cost is high and construction and transportation are inconvenient. High-temperature welding is used in some of the geocells, which made them very likely to a tear of the welds in the engineering application. The preparation of welding process of the traditional ultrasonic welding is relatively complex and many instability factors increase. Some geocells bear large load for a long time until exhaustion and cause great deformation when applied into soft soil foundation treatment. It failed to take effective measures to cope with destruction.

Therefore, with the harsher engineering construction geological conditions and the higher global market's requirements for intelligence, security stability, ageing resistance and good component connection function of geocell, it's an urgent need to develop and study more intense, more stable, safer and more adaptable new-type of geocell to meet the requirements of construction engineering development.

\section{AN OVERVIEW OF A NEW-TYPE OF GEOCELL}

\subsection{Characteristics and Adaptability}

Safety forewarning composite integral strong geocell is a reticular cell which is first made into sheet by special polymer materials and then formed into stereoscopic space three-dimensional structure by special methods and process. The diagrammatic sketch is shown in Fig. (1). The safety forewarning function is achieved by punching in the geocell, bringing in armor cable in the construction and monitoring stress variation. Special ultrasonic welding process is adopted in the joint, thus the chemical bond is not damaged and is consistent with the non-joint, which ensures the strong integrity and stability of geocell. Because of its good scaling and telescoping for the convenient transportation, it forms a high-strength structure with filler [16-18].

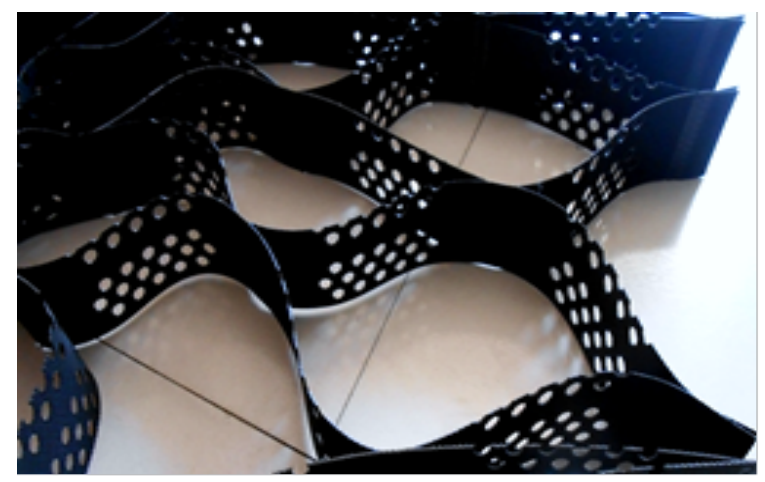

Fig. (1). Diagrammatic sketch of geocell.
Safety forewarning composite integral strong geocell can be applied to some difficult engineering fields such as reinforcing the road soft foundation of sandy soil, strengthening the railway subgrade under complex conditions and protecting the high slope of the airports and ports [19-22].

\section{DEVELOPMENT AND INNOVATION}

\subsection{The Technical Route of Development}

The manufacturing process of the product development is shown in Fig. (2).

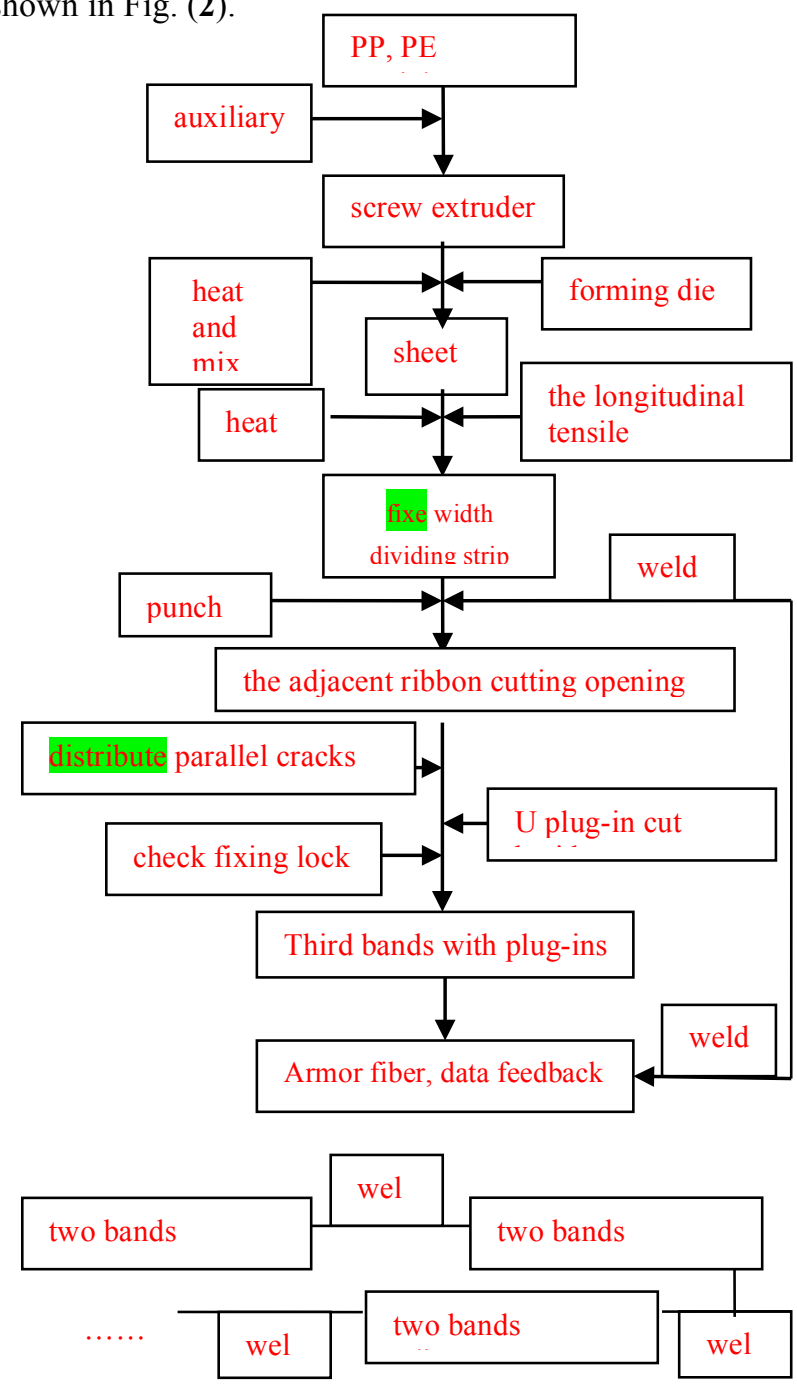

Fig. (2). Manufacturing process of geocell.

(1) After the formula mixing of PP and PE particles and the auxiliary, which is collaborated by Changchun Institute of Applied Chemistry of Chinese Academy of Sciences, including heating and mixing with screw extruder, the sheet is made by molding.

(2) After heating, the sheet has the longitudinal tensile to make the molecular chain of polymer materials arranged in orientation and the tensile strength reaches the highest value $250 \mathrm{MPa}$.

According to the requirements of product design, the sheet after stretching is divided into strips of certain 
width. Punching in the strips with the need of the project in order to let the intelligent optical fiber coated with armor penetrate.

(4) Two adjacent strips coincide to have the cutting opening (in the length direction of the strip). The parallel cutting is distributed in the width direction of the strip and the space between them is $5-15 \mathrm{~mm}$.

(5) The two openings of the U-plug are staggered through the cuttings of two strips in sequence. At the same time, the two strips are woven together and the openings are locked by retaining fixed locking plate to prevent the plug off.

(6) When the third strip is coinciding, install the plug on the cuttings of adjacent strips in the middle position of two adjacent plugs, and the like, continuously repeated.

(7) Along the length direction of the strip, the armor fiber is penetrated through the holes in the strips, with the surface in an $\mathrm{S}$ shape. They are connected with the information acquisition system through optical fiber and has the function of data feedback and safety forewarning; providing internal structure environmental change of engineering to prevent engineering accidents.

(8) Uniform welding with special ultrasonic welding process after connection does not affect the microcosmic properties of the material and make the connection even as a whole to the maximum strength.

\subsection{Innovation of Application Technology}

(1) On the basis of great enhancement of the indexes as joint tensile strength and sheet tensile yield strength, safety forewarning composite integral strong geocell introduces the concept of optical fiber and is connected by armor fiber coated with special armor. When there's anti-stress change in engineering, the optical signals are collected by grating demodulator and the monitoring system analyzes the data to implement the engineering safety forewarning. It fills the domestic void and is an application innovation in the field of engineering application.

(2) The dedicated closed lock connection technology is invented to prevent the occurrence of dislocation, loosening and falling off. Its direction can be arbitrarily chosen and the technical level reaches to the leading level domestically.

\section{EXPERIMENTAL STUDIES ON MECHANICAL PROPERTIES}

\subsection{The Tensile Test of Strong Geocell}

\subsubsection{The Experimental Device and Scheme Design}

The strong geocell is of reticular structure whose deformation is not only related to the load application, but also to the temperature and time which affects the geocell significantly. In the process of the test, error is inevitable because of the methods, conditions and personnel of the test. So the free tensile test of geocell at room temperature is carried out in the ideal condition. In order to ensure the authenticity and reliability of the test data, the $0.5 \mathrm{~m} \times 0.5 \mathrm{~m}$ traditional geocell is chosen to have the comparison with the new-type one. The test cell is firmly fixed with the built-in girder by the grip, and the lower end is connected with the heavy objects for loading. Observe and record the deformation of the geocell at different times in the effect of $300 \mathrm{~kg}, 500 \mathrm{~kg}$ and $800 \mathrm{~kg}$, and analyze the deformation law under different stresses. After a period of observation, unload and record the residual deformation and calculate elasto-plastic deformation under different effects.

\subsubsection{The Analysis of Test Results}

Get the statistics of the data and results in the test process and draw the following curve with the statistical results. The stress-elongation curve of the two geocells is shown in Fig (3).The elongation-time relationship of the new-type of geocell is shown in Fig. (4). The elongation-time relationship of the traditional geocell is shown in Fig. (5). The tensile strength statistics of the two geocells in the test are given in Table 2.

Analysis of the test data in the above charts gave the following results:

(1) From the analysis of the test results of the three groups, there's great deformation found in the two kinds of geocells at the beginning. But the deformation slows down or nearly stops after a period of time. The size of loading has a significant impact on the rheology of the geocell under the same temperature conditions. The greater the stress is, the greater the elongation and the longer the time to achieve stability.

Table 1. Comparison of technical and economic indexes of two kinds of cell products.

\begin{tabular}{|c|c|c|c|c|}
\hline \multirow{2}{*}{ Serial Number } & \multirow{2}{*}{ Classification } & \multirow{2}{*}{ Unit } & Traditional Products GB/T19274-2003 & Composite Integral Strength of Geocell \\
\cline { 4 - 5 } & & & $100<\mathrm{H}<200$ & $50<\mathrm{H}<200$ \\
\hline \hline 1 & Geocell height & $\mathrm{H} / \mathrm{mm}$ & $\mathrm{T} \geq 1.1$ & $0.5<\mathrm{T}<1$ \\
\hline 2 & Cell sheet thickness & $\mathrm{T} / \mathrm{mm}$ & $330 \leq \mathrm{A}<800$ & $330 \leq \mathrm{A}<800$ \\
\hline 3 & Cell group spacing & $\mathrm{A} / \mathrm{mm}$ & No & Yes \\
\hline 4 & Safety warning & - & $\leq 24$ & $\geq 34$ \\
\hline 5 & Economic benefits (price) & yuan $/ \mathrm{m}^{2}$ & & \\
\hline
\end{tabular}




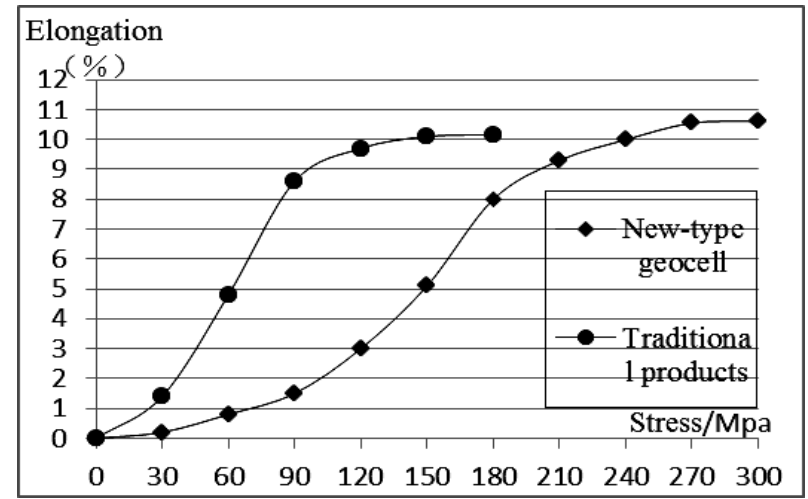

Fig. (3). The stress-elongation curve of the new-type of geocell and traditional geocell.

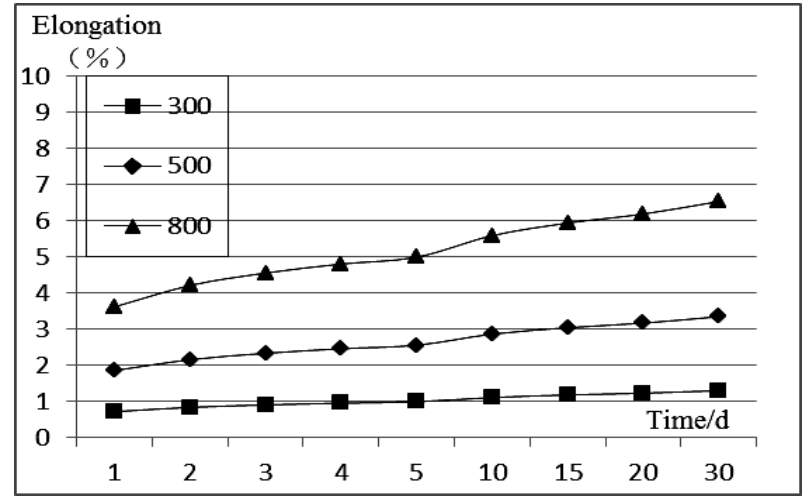

Fig. (4). The elongation-time relationship of the new-type one.

As is shown in the tensile test results of the two groups of geocells, at the same time and under the same stress, the elongation of geocell is an $\mathrm{S}$ curve with the change of stress, and it gradually slows down as time goes on and remains stable. Therefore, we can see that the material of geocell is of low modulus and high creep. When it is applied to the specific engineering, if the deformation keeps in allowable range in a period of time after completion, the engineering is regarded as being safe.

(3) As is shown in Figs. (3-5) and Table 2, the strength and integrity of the new-type of geocell are greater than that of the traditional one and has less deformation in the same loading effect. This is mainly because of the traditional plastic sheet strip that is molded by extrusion and is not stretched. The node is made by ultrasonic thermo fusion welding which strength is only $200 \mathrm{~N} / \mathrm{cm}$. It is extremely easy to crake. Since special ultrasonic welding process is adopted in the strong geocell, the molecules of the joint are arranged in orientation when welded and the chemical bonding is not damaged to ensure the maximum tensile strength of products. It is far greater than the node strength of traditional connection technique. Collaborated with Changchun Institute of Applied Chemistry of Chinese Academy of Sciences, composite integral strong geocell is developed with a special tensile process and the node strength is $\geq 2000 \mathrm{~N} / \mathrm{cm}$, which exceeds the traditional geocell by more than 10 times.

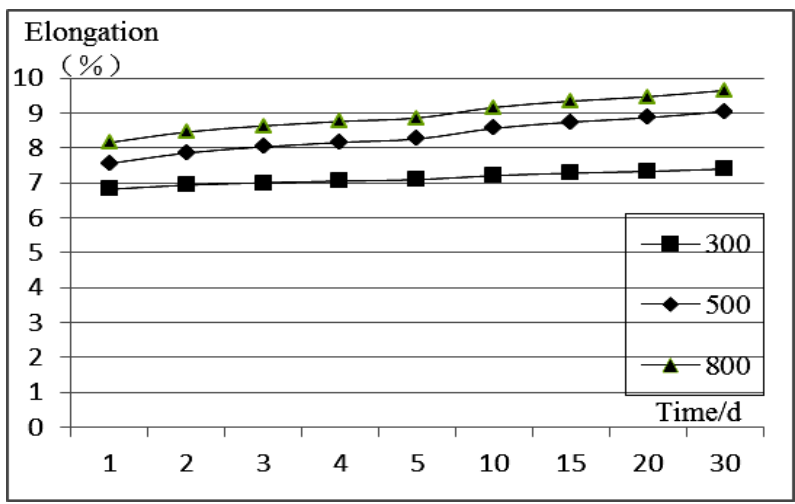

Fig. (5). The elongation-time relationship of traditional geocell.

\section{NUMERICAL SIMULATION ANALYSIS}

From the parameter value of geocell measured in the test, FLAC ${ }^{3 \mathrm{D}}$ is used to simulate the pullout test. The length $\times$ width $\times$ height of the simulation region of the model is $5 \mathrm{~m} \times 5 \mathrm{~m} \times 6 \mathrm{~m}$. There are three layers of geocell in the model. Only the middle layer is used to have the pullout test simulation after compaction. The model is divided into 27000 units and 29791 nodes and the FLAC $^{3 \mathrm{D}}$ three-dimensional simulation established is shown in Fig. (6). Fig. (7) is the stress nephrogram vertical view of geocell in $\mathrm{X}$ direction. Fig. (8) is the

Table 2. Tensile test data comparison of security forewarning composite integral strong geocell and traditional geocell.

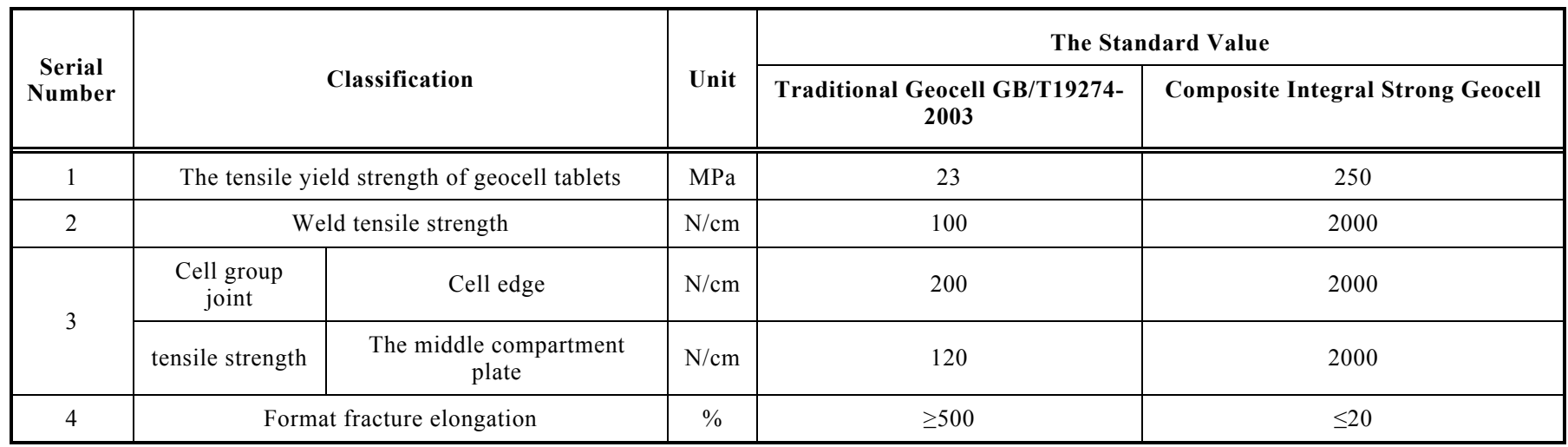


stress nephrogram in $\mathrm{X}$ direction. Fig. (9) is the overall displacement nephrogram. Fig. (10) is the displacement curve of geocell in $\mathrm{Z}$ direction and Fig. (11) is relationship curve of pullout rate and time pace of geocell in $\mathrm{X}$ direction.

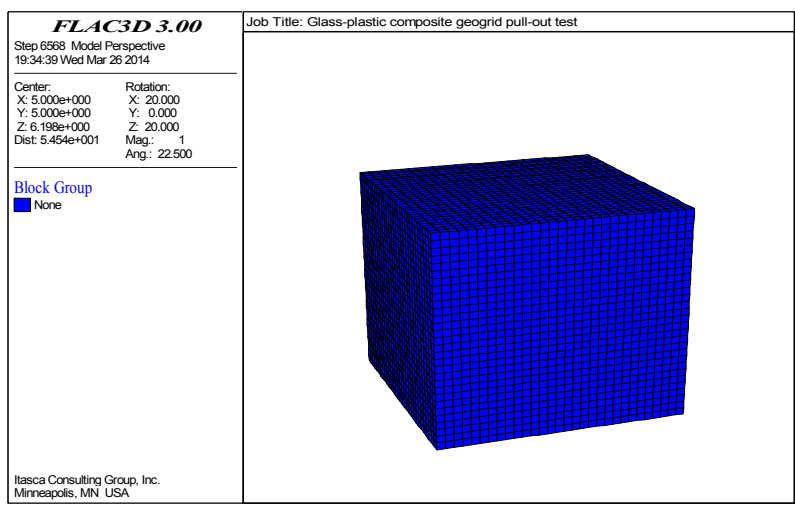

Fig. (6), Three-dimensional numerical simulation model.

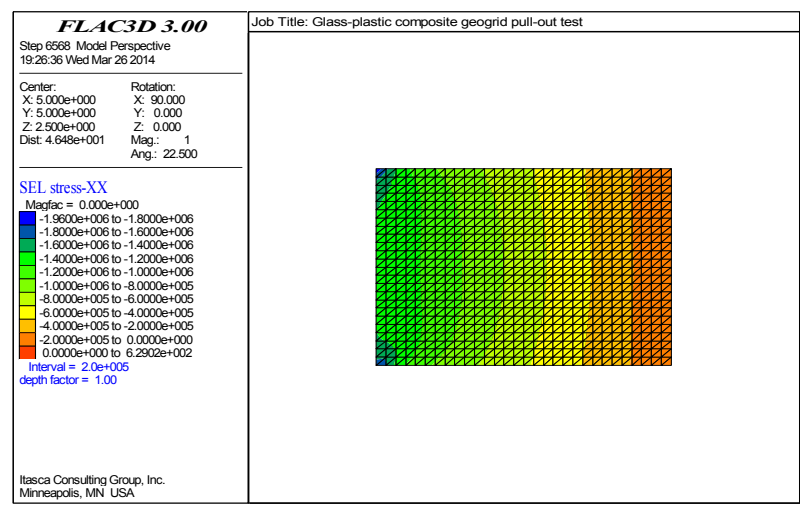

Fig. (7). Stress nephrogram vertical view of geocell in $\mathrm{X}$ direction.

From the analysis of Figs. $(6,7)$, the maximum stress of geocell in $\mathrm{X}$ direction appears in the left of nephrogram, which is $1.96 \times 10^{6} \mathrm{~Pa}$, and decreases gradually along $\mathrm{X}$ direction.

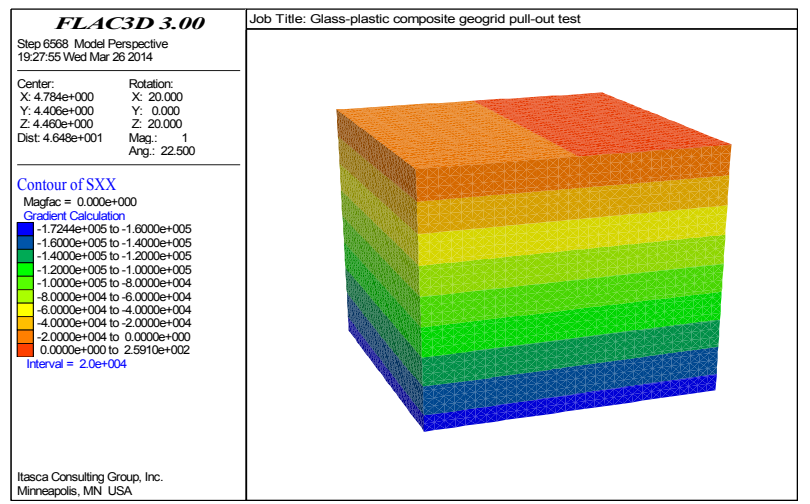

Fig. (8). Stress nephrogram in $\mathrm{X}$ direction.

From the analysis of Fig. (8), the overall stress of the geocell decreases gradually from the top down along $\mathrm{X}$ direction and the maximum appears on the top which is $1.72 \times 10^{5} \mathrm{~Pa}$.

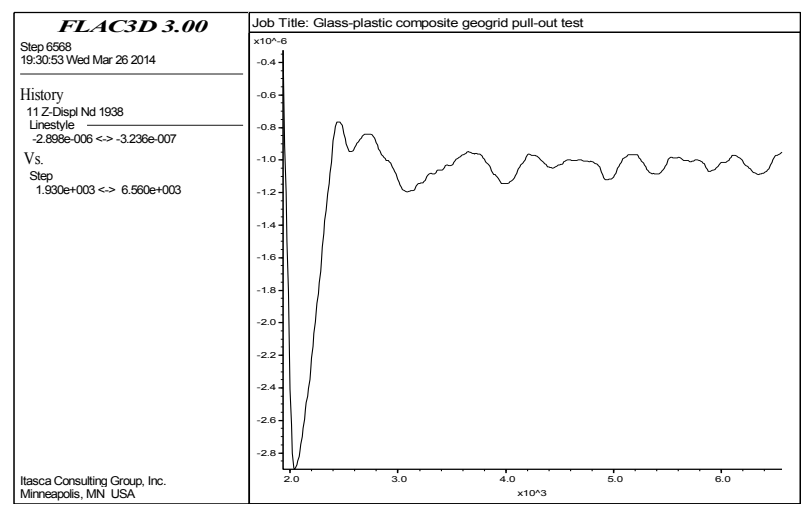

Fig. (9). The overall displacement nephrogram.

From the analysis of Fig. (9), in the process of pullout test, the overall displacement decreases gradually from top down. The displacement value at the bottom is 0 and the maximum value is on the top which is $1 \times 10^{-2} \mathrm{~m}$.

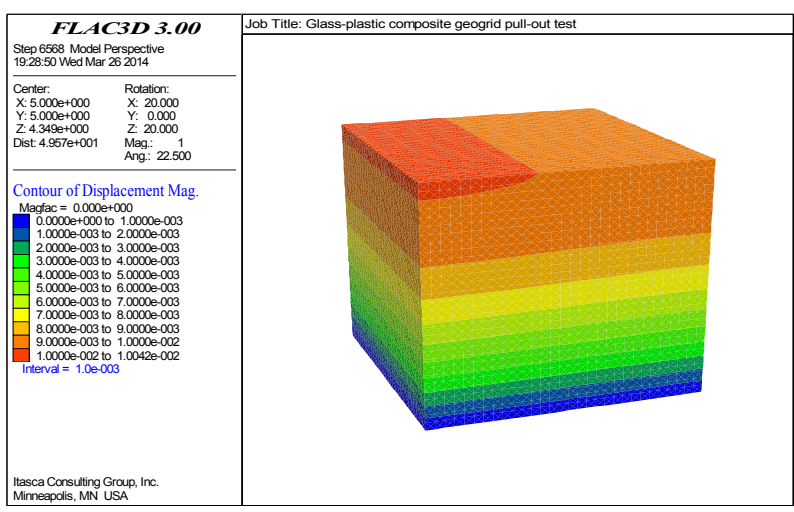

Fig. (10). Displacement curve of geocell in $\mathrm{Z}$ direction.

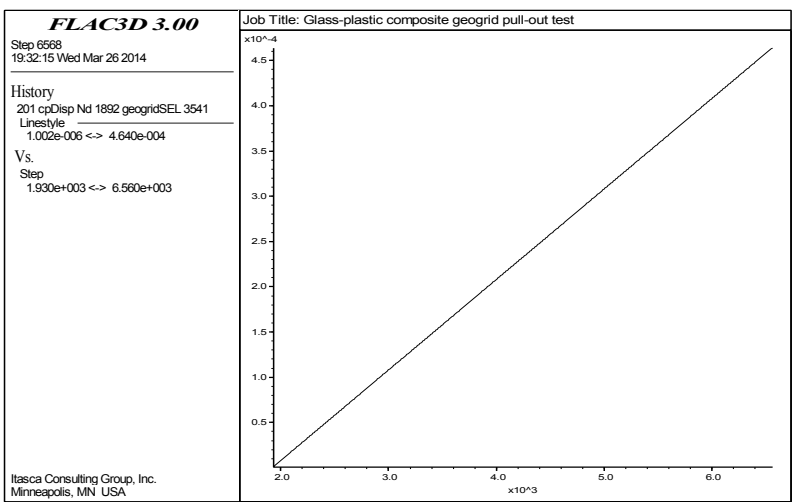

Fig. (11). Relationship curve of pullout rate and time pace of geocell in $\mathrm{X}$ direction.

From the analysis of Figs. $(\mathbf{1 0}, \mathbf{1 1})$, in the pullout process of the middle layer of geocell, the displacement in $\mathrm{Z}$ direction increases gradually and the maximum value is $1 \times 10^{-6} \mathrm{~m}$. The displacement bounces up and down after the peak and reaches stability at last. There's a linear relationship between the pullout rate and time pace along $\mathrm{X}$ direction. In the process of the pullout test, elongation shows an S curve with the change of stress and has flatlined basically after stability, which is consistent with the elongation-stress curve and stress-time curve in the 
indoor pullout test. So it is relatively rational to have the indoor pullout test of the new-type geocell.

\section{DISCUSSION}

At present, the strength, stiffness and stability of geocell are difficult to meet the actual needs of the complex engineering. The development techniques of a new-type of geocell improve its mechanical properties and introduce new techniques to make the study of geocell intelligent and digital. In the process of the test, numerical simulation is done to the new-type of geocell in order to verify its rationality. Since there's less domestic research on the new composite materials as geocell and lack of reference model and scheme of numerical simulation, the model abstracts the geocell into a crisscrossing three-dimensional reticular structure. Special ultrasonic welding is used to connect the geocells and the force loss caused by compaction in the process of structure formed of packing and geocell is neglected. Only the middle layer is stretched during the stretching process. Assuming the tension acts directly on the geocell and the error caused by the two ends is ignored. Assuming the test is carried out at room temperature, without considering the influence on the simulation results of geocell. The mechanical properties of the geocell are simulated, and the numerical results and error accord with the design standard in the absence of the specific model, thus providing reference for the research of geocell.

\section{CONCLUSION}

(1) Through studying the traditional manufacturing process of geocell, combined with the problems facing in the field of construction and using the new techniques such as special ultrasonic welding process, intelligent optical fiber technology and retaining fixed locking plate technology, the technique route of the development and innovation technology of new-type of geocell is put forward. It helps develop a safety forewarning new-type of strong geocell.

The mechanical properties of new-type of geocel are studied by the tensile test and creep test, and compared with the traditional geocell. The elongation-stress law and loading-time law are studied, and the actual application value of the tensile yield strength and tensile strength are determined to provide theoretical basis for engineering design and construction.

The mechanical properties of the new-type of geocell are simulated by $\mathrm{FLAC}^{3 \mathrm{D}}$ numerical simulation and the relationship between strain and stress, and time and displacement has been analyzed. The safety design and construction of a new-type of geocell is suggested according to the actual situation of simulation.

(4) The innovation points of the new-type of geocell include the optimization process of the overall tensile yield strength, the fall proof technique of the locking plates, positioning and monitoring technology, which effectively solves the special engineering geological problems such as ecological afforestation, sand fixation and erosion controlling, and the treatment of high slope soft soil foundation. The new design can save costs and ensure the quality of the project.

\section{CONFLICT OF INTEREST}

The author confirms that this article content has no conflict of interest.

\section{ACKNOWLEDGEMENTS}

This work was financially supported by: (1) National Natural Science Foundation of China (NSFC) (41372289); (2) SDUST Research Fund (2014TDJH103); (3) A Project of Shandong Province Higher Educational Science and Technology Program (12LH03); (4) China's Post-doctoral Science Fund (2012M521365).

\section{REFERENCES}

[1] Zhao Ming-hua, Long Jun, Zhang Ling, et al. Comparative analysis of model tests on different types of composite foundations. Chinese Journal of Geotechnical Engineering, 2013; 35: 611-8.

[2] Yang Minghui, Deng Yuebao, Zhao Minghua. Study of stiffness test method of geocell cushion based on superposed beam theory. China Civil Engineering Journal 2011; .44(88); 88-93.

[3] Tafreshi S N, Khalaj O, Dawson A R. Repeated loading of soil containing granulated rubber and multiple geocell layers. Geotextiles and Geomembranes 2014; 42: .25-38.

[4] Emersleben A, Meyer N. The use of vertical columns in combination with geocell stabilized load transfer platforms for the construction of roadways over soft soils. Bridges, 2014; 10: 121.34 .

[5] Song F, Cao G R, Zhang L Y, et al. Numerical Analysis of Failure Mode of Geocell Flexible Retaining Wall. Bridges 2014; 10: 127-28.

[6] ZHAO Ming-hua, CHEN Bing-chu, HUANG Li-kui. Model Test of Geocell Reinforced Low Embankment and Rigid Pavement System. China Journal of Highway and Transport, 2011;24: 1 -6.

[7] Wang Guangyue, Han Yan, Wang Xinghua. Large room under the condition of rainfall the stability analysis of flexible revetment. Geotechnical Engineering 2012; 10: 3020-24.

[8] Zhao Minghua, Chen Bingchu, Yin PingBao, etc. Large chamber structure layer shear performance test research. Highway Traffic Science And Technology 2012; 577-81.

[9] Bian Xue-cheng, Song Guang Chen Yun-min. Pasternak foundation in the large room of geotextile stress deformation analysis. Journal of engineering mechanics 2012; 29: 147-55.

[10] SUYonghua, LUO Zhengdong, CHANG weitao. Sensitivity analysis of the Reinforced Cut and Fill Sub-grade Distortion Factors Based on Simulation Test.Journal of Hunan University(Natural Sciences) 2011; 38: 12-6.

[11] SONG Fei, XU Wei-qiang. Numerical analysis of deformation behavior of geocell flexible retaining wall. Rock and Soil Mechanics 2011; 32: 739-43.

[12] Han J, Thakur J K, Corey R, et al. Assessment of QC/QA Technologies for Evaluating Properties and Performance of Geosynthetics in Roadway Systems. Bridges 2014; 10: 121-39.

[13] Song Fei, Xie Yong-li Yang Xiao-hua. Fill side effect when loading large chamber of flexible retaining wall failure mode study. Journal of geotechnical engineering 2013; 35: 152-5. 
[14] Tafreshi S N M, Javadi S, Dawson A R. Influence of geocell reinforcement on uplift response of belled piles. Acta Geotechnica 2013; 1-16.

[15] Sear T R, Elliott P C, Chapman T W. Kinnickinnic River Flood Management and Watercourse Rehabilitation: Milwaukee, Wisconsin. Bridges 2014; 10: 312-6.

[16] Wang Qingbiao, Wen Xiaokang, Zhang Cong, Shi Zhenyue. Glass and plastic composite geotechnical studies on the development and application of grid. Journal Of Composite Materials 2013; 30: 300-5

[17] Zhu Jianhai, Gu Liangjun. Large chamber in railway bed weak reinforcement application. Journal of Transportation Engineering 2011; 6: 105-8.

[18] WANG Guang-yue, HAN Yan, WANG Xing-hua. Stability analys-is of geocell flexible slope protection in rainfall. Rock and Soil Mechanics 2012; 33: 3021-5.
[19] SHI Li-guo, ZHANG Meng-xi, CAO Peng. Triaxial shear stren-gth characteristics of lime-soil reinforced with polypropylene fiber inclusions. Rock and Soil Mechanics, 32; 2721-8.

[20] Özer A T, Akay O, Fox G A, et al. A new method for remediation of sandy slopes susceptible to seepage flow using EPS-block geofoam. Geotextiles and Geomembranes 2014; 42 : 166-80.

[21] Corey R, Han J, Khatri D K, et al. Laboratory Study on Geosynthe-tic Protection of Buried Steel-Reinforced HDPE Pipes from Static Loading.Journal of Geotechnical and Geoenvironmental Engineering 2014

[22] ZHANG Ling, ZHAO Ming-hua, MA Bin-huil. Large Scale Laboratory Experiments on Two-directional Composite Foundation Reinforced with Geocell and Stone Columns. China. Journal of Highway and Transport 2013; 26: 1-8.

Received: May 26, 2015

Revised: July 14, 2015

Accepted: August 10, 2015

(C) Qingbiao et al.; Licensee Bentham Open.

This is an open access article licensed under the terms of the Creative Commons Attribution Non-Commercial License (http://creativecommons.org/licenses/ by-nc/4.0/) which permits unrestricted, non-commercial use, distribution and reproduction in any medium, provided the work is properly cited. 